\title{
Topic Structures and Minimal Effort
}

\author{
Yen-Hui Audrey Li \\ University of Southern California, Los Angeles \\ audreyli@rcf.usc.edu
}

The complexity of human languages has always inspired research for some human faculty that makes language learning possible. The system that generates the complexity of human languages, ideally, is simple and effective. Recent developments of the generative grammatical theory explore deeper into the issue of simplicity or economy. The Minimalist Program developed in Chomsky $(1991,1993,1995)$ tries to provide contents to such notions. What does it mean to be more economic or least effort? An important instantiation of such notions is the proposal that movement is the last resort assuming that movement is more costly than non-movement. ${ }^{1}$ Processes occur only because they are necessary. The definition of necessity generally is cast in morphological terms. Moreover, the notion of "economy" or "least effort" is deterministic of the appropriate derivations for sentences: a shorter derivation is better than a longer one. In this work, we show that the notion of "least effort," - do minimally if possible - is manifested not only in derivations but also in other aspects of the grammar. We take Chinese ${ }^{2}$ as an example and show that this language exhibits the properties manifesting some "least effort" guidelines in the area of movement and reconstruction, and in the projection of syntactic positions: when there is a choice, non-application of movement/reconstruction and non-projection of a position are adopted. ${ }^{3}$ These phenomena essentially are attested in topic structures. The question arises as to why topic structures exhibit such minimal effort effects. We suggest that this is due to the fact that topic structures can be derived by movement or base-generation. When there are morpho-syntactic clues that reconstruction is necessary, the structure is a movement structure. Otherwise, the less costly non-movement structure is assumed. Moreover, because of the possibility of assuming a topic $\mathrm{NP}^{4}$ to be base-generated, bearing a predication (or aboutness) relation with the comment clause, the argument position which otherwise would be related to the topic (conveniently termed the trace position) is not projected when there is a choice of projecting or not projecting it.

1 An implicit assumption is that movement is more costly than non-movement, cf. the Minimalist Program presented in Chomsky 1991, 1993, 1995.

2 In this work, we concentrate on Mandarin Chinese.

3 See note 1. This claim basically concerns topicalization in Chinese. It contrasts with the claim by Aoun and Benmamoun (1998), Aoun, Choueiri and Hornstein (1999) that movement is a primary strategy in Lebanese Arabic (LA). The LA data have to do with $w h$-movement. It is possible to surmise that constructions differ in taking movement or non-movement as the primary strategy. Wh-movement concerns operator movement. Topicalization, if we follow Ning (1993)'s analysis, concerns XP fronting, rather than operator movement. Note that they also differ in reconstruction possibilities; see section 1.2.

4 This work does not distinguish NPs and DPs (see Abney 1987 for the proposal on DP structures and Li 1998, 1999 for arguments for the existence of DPs in Chinese). 
The working of minimal effort in the area of movement and reconstruction as manifested in Chinese topic-structures is discussed in section 1. Section 2 discusses the relevance of minimality in the projection of syntactic structures, as illustrated by the behavior of the some structures containing ambiguous verbs, especially with respect to topicalization possibilities.

\section{Minimal movement/reconstruction}

Chinese does not have many overt movement structures. A likely candidate that has been the subject of substantial discussions is the topic structures. There have been long debates on whether topic structures are derived by movement (see, for instance, Huang 1982, 1987, Li 1990, Qu 1994, Shi 1992, Shyu 1995, Xu 1986, Xu and Langendoen 1985). Even though it is possible that certain topic structures might be base-generated (but see Shi 1992 who claims that all topic structures are derived by movement), there is some clearer evidence that topic structures should be able to be derived by movement. ${ }^{5}$ On the other hand, there is also conflicting evidence that movement cannot be the proper derivation because of the failure of reconstruction. To reconcile the conflicting properties, we suggest that the grammar should have the notion of minimal effort when reconstruction applies - reconstruct only when necessary. Taking a step further and approaching the issue from a broader perspective, we suggest that it is the ambiguity of a topic structure - movement or base-generation - that allows minimal reconstruction.

\subsection{Topic structures - movement as an option}

Let us begin with the arguments that topic structures need to have a movement option. Essentially, the arguments against a movement analysis of topic structures rely on the existence of an empty pronoun in Chinese. If an empty pronoun is available and can be interpreted, in the same way as an overt pronoun, as coreferential with or bound by the topic (such as (1ab)), why is there a need to adopt a movement structure for topic constructions?

a. Zhangsan,$\left[\begin{array}{ll}e_{i} & k a n d e\end{array}\right]$ shu $]$ henduo.

Zhangsan read De book many

'Zhangsan, the books he has read are many.'

b. Zhangsan ${ }_{i},\left[\left[\mathrm{ta}_{i}\right.\right.$ kan de $]$ shu $]$ henduo.

Zhangsan he read De book many

'Zhangsan, the books he has read are many.'

If ( $1 \mathrm{~b}$ ) is possible, there needs to be an option that a topic is base-generated and a pronoun in the comment clause is coindexed with the topic. If this option is available and if an empty pronoun behaves like an overt pronoun, why is there a need to adopt a movement approach to topic structures?

5 The disagreement on deriving topic structures by movement often centers on the possible interpretations of empty pronouns and how empty pronouns should be identified. See, for instance, the works by $\mathrm{Xu}$ and Huang as cited in the text. 
The problem of incorporating (1a) to (1b) is that there are more restrictions on when and where an empty pronoun can occur. Our arguments for the need of a movement derivation for topic structures therefore come from those cases illustrating when and where an empty pronoun can occur. First consider the evidence from the distribution of prepositional phrases (PPs). Saito (1985) observes that a pro cannot be a PP and therefore a displaced PP must be the result of movement rather than coindexing with a base-generated pro. Chinese topic structures allow a PP to be a topic. If a PP cannot be base-generated because of the lack of a PP pro, the topic PP must be the result of topicalization. ${ }^{6}$

(2) a. Dui Zhangsan, wo zhidao ta $t$ bu zenme guanxin.

to Zhangsan I know he not how care

'To Zhangsan, I know he does not quite care for.'

b. Cong zhejia yinhang, wo zhidao women keyi t jiedao henduo qian. from this bank I know we can borrow much money 'From this bank, I know we can borrow a lot of money.'

c. Gen zhe zhong laoshi, wo zhidao wo t yiding xue-bu-hao with this kind teacher I know I certainly study-not-well 'With this kind of teacher, I know I certainly will not learn well.'

The second piece of evidence for the need of a movement approach to topic structures comes from the distribution of idiomatic expressions with the form $[\mathrm{V}+\mathrm{O}(\mathrm{bject})]$. The $\mathrm{O}$ of a $\mathrm{V}+\mathrm{O}$ idiom can be a topic: ${ }^{7}$

(3) a. wanxiao/mo/dao, ta $\mathrm{kai} / \mathrm{you} / \mathrm{kai}$ de hao ma? joke/-mor/knife he open/hu-/open DE well Q 'Does he joke/humor/operate well?'

b. mo, ta shi hui you, keshi changchang you de buhao -mor he be can hu-but often hu-DE not good 'He can humor but not quite well.'

6 Huang (1982, 1989)'s generalized control rule governing the distribution and interpretation of pro has been challenged (for instance, Xu 1986, Xu and Langendoen 1985. The adoption of such a control rule, nevertheless, will disallow ( $2 \mathrm{a}-\mathrm{c}$ ) to contain a pro. Huang's generalized control rule requires a pro to be identified with the closest c-commanding NP (which accounts for (la)). The empty category associated with the topic PP in (2a-c) cannot be a pro because identification with the closest c-commanding NP (the subject of the clause where the empty category occurs) will create a Binding Principle B violation.

7 Idiomatic expressions sometimes are hard to be distinguished from figurative speech (see Goodall 1987 , 1989, Huang 1990, Sybesma 1999). The example of youmo, a transliteration of a bisyllabic 'humor' into a bisyllabic word and being reanalyzed as a V+O compound, discussed in Huang (1984), may be taken as a clearer example of idioms. Many other idiomatic V+O expressions generally assumed as such in the literature allow topicalization as well.

(i) bian ta yizhi da/xiao-bu-chulai, (zenme ban?)

convenience he still big/small-not-out how do

'He still cannot make bowel movement/urinate (what to do?)' 
It is widely accepted that the displacement of an idiom chunk is evidence for movement because the parts of an idiom need to be a unit at some level of the derivation.

If we claim that the cases in (2-3) are derived by movement, they should behave like movement structures. For instance, they should obey the locality constraint on movement. This is true. The topic in (2-3) cannot be coindexed with an empty category inside an island. (4a) shows that long distance movement is possible; however, the movement cannot cross an island boundary $(4 \mathrm{~b}-\mathrm{c})$.

(4) a. $\mathrm{mo}_{\mathrm{i}}$, wo zhidao ta shi hui you $\mathrm{e}_{\mathrm{i}}$, keshi changchang you $\mathrm{e}_{\mathrm{i}}$ de buhao -mor I know he be can hu- but often hu DE not good

'-mor (humor), I know that he can hu- (make) but often cannot hu-(make) well.'

b. ??mo $\mathrm{m}_{\mathrm{i}}$, Zhangsan renshi nage you guo $\mathrm{e}_{\mathrm{i}}$, keshi you $\mathrm{e}_{\mathrm{i}}$ de buhao de ren -mor Zhangsan know that hu- Asp but hu-DE not good '-mor(humor), Zhangsan knows the person who has hu-(made) but did not make well.'

(Humor, Zhangsan knows the person who can humor but not quite well.)

c. ?? $\mathrm{mo}_{\mathrm{i}}$, wo zhidao Zhangsan yinwei hui you $\mathrm{e}_{\mathrm{i}}$, hen you renyuan

-mor, I know Zhangsan because can hu- very have popularity

'-mor, I know Zhangsan is popular because he can hu-'

Similarly, the displaced PPs in (3) cannot come from within an island: ${ }^{8}$

(5)a. *[Dui Zhangsan $]_{\mathrm{i}}$, wo renshi [[ $\mathrm{e}_{\mathrm{i}}$ hen guanxin de] ren].

to Zhangsan, I know very care DE person

b. *[Cong zhejia yinhang $]_{i}$, wo renshi [[keyi $e_{i}$ jie henduo qian de $]$ ren] from this bank I know can borrow much money DE person

c. ${ }^{*}[\text { Gen zhe zhong laoshi }]_{\mathrm{i}}$, wo renshi $\left[\left[\mathrm{e}_{\mathrm{i}}\right.\right.$ yiding xue-bu-hao de] ren] with this kind teacher I know certainly study-not-well DE person

The relevance of island conditions cannot be accommodated by a base-generation approach.

In addition to the locality conditions, movement structures show reconstruction possibilities. Chinese topic structures seem to allow reconstruction, as illustrated by the following facts concerning the binding of anaphors.

A displaced anaphor can be bound by an antecedent that does not seem to c-command it:

(6) a. Zhangsan ${ }_{i}$ hen zhaogu (ta)ziji $i_{i}$ (de pengyou).

Zhangsan very care him self DE friend

'Zhangsan takes good care of (him)self/his own friends.'

8 An overt pronoun inside an island coindexed with a topic NP, not a topic PP, is acceptable. For instance:

(i) Zhangsan, wo renshi [[ dui ta hen guanxin de] ren].

Zhangsan, I know to him very care DE person

'Zhangsan, I know the people who care about him.' 
b. (ta)ziji $i_{i}$ (de pengyou), Zhangsan ${ }_{i}$ hen zhaogu.

him self DE friend Zhangsan very care

'(him)self/his own friends, Zhangsan takes good care of.'

c. Zhangsan/ Shei/ Nage ren/ Meiren / Meigeren ${ }_{\mathrm{i}}$ dou Zhangsan who which man noone everyone all hen xihuan ziji $i_{\mathrm{i}}$ hua de hua. very like self draw $\mathrm{DE}$ picture 'Zhangsan/Who/Which person/Noone/Everyone likes the picture that self drew.'

d. ziji $_{\mathrm{i}}$ hua de hua, self draw DE picture Zhangsan/ Shei/ Nage ren/ Meiren / Meigeren ${ }_{\mathbf{i}}$ dou hen xihuan' Zhangsan who which man noone everyone all very like 'The picture that self drew, Zhangsan/Who/Which person/Noone/Everyone likes.'

The anaphor binding facts here support the analysis according to which the topic is moved from a position c-commanded by the subject. After reconstruction (i.e., placing the moved topic back to the original position), the topic can be c-commanded and bound by the subject. The contrast between the pairs of the sentences in (7) further shows that reconstruction effects exist, if we take the existence of overt pronouns to be indications of instances of basegenerated non-movement structures: ${ }^{10}$

(7) a. (Ta)ziji $i_{i}$ de baba $a_{j}$, Zhangsan ${ }_{i}$ hui zhaogu $t_{j}$ himself DE father Zhangsan will care

'(Him)self's father, Zhangsan will take care.'

b. ??(Ta)ziji de baba b $_{\mathrm{i}}$, Zhangsan $_{i}$ hui zhaogu ta . $_{\mathrm{i}}$ himself DE father Zhangsan will care him

'(Him)self's father, Zhangsan will take care of him.'

In brief, the following facts argue for the need of a movement process to derive topic structures.

9 Some speakers do not quite like the preposed anaphor to be taziji, especially when the binder is a QP or a wh-operator.

10 The contrast between (7a) and (7b) shows that reconstruction in the sense of placing elements back, not just coindexing, is needed for the topic anaphor to be bound by its antecedent. This view of reconstruction also fares better in our discussion of minimal effort, as it is less clear how other formulations of reconstruction, such as the chain theory (see Barss 1986, chains consisting of the moved element and its trace(s)) or copy and merge theory (Chomsky 1995), can be phrased in terms of minimal effort. See the discussions in section 1.2. 
(8) i. A PP, which cannot be a pro, can be topicalized

ii. Part of an idiomatic expression can be topicalized.

iii. The displaced PP or idiom chunk can be separated from its original position across clauses (long distance dependency relation) but cannot be separated by an island boundary (island conditions)

iv. Reconstruction is possible as illustrated by the binding of anaphors.

The last point is based on the type of examples given so far, which contain anaphors in the topic position at the beginning of a sentence. These examples show that reconstruction is available, which argues for the existence of movement. However, when more data are examined, it is no longer clear that reconstruction is always possible in topic structures. The lack of reconstruction in topic structures in fact has been noted in the experimental studies by Chien et al (1993). In their experimental study of reflexive binding, they find that adults, as well as children, "rarely allowed taziji [and $z i j i$ ] to be backward chain-bound by the embedded subject NP that followed" (p. 250) the reflexive. Examples they used are (9a-b):

(9) a. Milaoshu mengjian, ziji-de qiqiu, Daxingxing zhuazhe. (p.241)

Micky Mouse dream, himself's balloon, Big Gorilla grasp

'Micky Mouse is dreaming that, himself's balloon, Big Gorilla is grasping'

b. Milaoshu mengjian, taziji-de erduo, Daxingxing mozhe. (p.247)

Micky Mouse dream, himself's ear, Big Gorilla touch

'Micky Mouse is dreaming that, himself's ear, Big Gorilla is touching'

The contrast between (6-7) on the one hand and (9a-b) on the other is surprising. All of these sentences are illustrations of anaphor binding via reconstruction; yet, the former is much better than the latter. (9a-b) can be further contrasted with (9c-d) where the "backward chainbinding" seems to be more Jikely, as the sentences are fully acceptable:

c. ziji-de qiqiu, Daxingxing zhuazhe.

himself's balloon, Big Gorilla grasp

'himself's balloon, Big Gorilla is grasping'

d. taziji-de erduo, Daxingxing mozhe.

himself's ear, Big Gorilla touch

'himself's ear, Big Gorilla is touching'

(9a-b) are not isolated phenomena. There are other facts that do not show reconstruction effects. For instance, if the anaphor is of the same/different type, we do not get reconstruction interpretations:

11 Picture recognition/yes-no tests, rather than act-out tests, were used, which supposedly would be better tests to find out possible interpretations, not just preferences. The results of the tests do not distinguish ziji from taziji with respect to the possibility of reconstruction. Cf. Huang and Tang (1988), Katada (1991) that distinguish taziji (and ziji contained in an NP for Katada) from the bare ziji with respect to reconstruction . 
(10) a. Zhangsan he Lisi hen xiang yao xiangtong/butong de dongxi Zhangsan and Lisi very want same/different De things 'Zhangsan and Lisi want same/different things.'

b. xiangtong/butong de dongxi, Zhangsan he Lisi hen xiang yao. same/different De things, Zhangsan and Lisi very want 'Same/Different things, Zhangsan and Lisi want'

c. Mei dui Zhongguo fufu dou hui jieshao xiangtong/butong de xuesheng. every pair Chinese couple all will introduce same/different De student 'Every Chinese couple will introduce same/different students'

d. xiangtong/butong de xuesheng, mei dui Zhongguo fufu dou hui jieshao. same/different De student every pair Chinese couple all will introduce 'Same/Different students, every Chinese couple will introduce.'

Each of the two pairs of sentences is not equivalent to the other in interpretation: (10a) and (10c) are ambiguous: 'same/different' can covary with Zhangsan and Lisi/the couple, or 'same/different' simply describes the things/students and does not covary with the subject. In the topic structures $(10 \mathrm{~b})$ and $(10 \mathrm{~d})$, the covariant reading is lost. In other words, the topic 'same/different' expressions are not reconstructed for interpretation.

Similarly, a topicalized $w h$-word does not have the scope interpretation of the nontopicalized counterpart. Thus, when a verb like xiang-zhidao 'want to know, wonder' is subcategorized for an interrogative, the embedded $w h$-word cannot be topicalized (11b), unless the embedded clause contains another question word, interpreted as an indirect question, and the topic $w h$ is interpreted as having scope over the entire sentence (11c).

(11) a. ta xiang-zhidao shei yao lai.

he want-know who want come

'He wonders who wants to come.'

b. *shei, ta xiang-zhidao yao lai.

who he want-know who want come

'Who, he wonders wants to come.'

c. shei, ta xiang-zhidao yao-bu-yao lai.

who he want-know want-not-want come

'Who, he wonders whether (he) wants to come.'

Other quantifier interaction facts point to the same generalization: the topic does not have the scope interpretation of the non-topicalized counterpart, i.e., reconstruction does not take place. The contrast in (12a-b) are examples of the scope interaction between quantifier phrases and $w h$-phrases and (13a-b), examples of the scope interaction between quantifier phrases. 
(12) a. Ta gei meige haizi zuo le shenme dongxi?

he for every child make Asp what thing -ambiguous

'What did he make for every child?'
(answered by 'he made a horse for Billy, a dragon for Jill...' or 'he made toys for every child')

b. Shenme dongxi, ta gei meige haizi zuo le $t$ ?

what thing he for every child make ASP -unambiguous

'What is it that he made for every child?'

(answered by 'toys, he made for every child.')

The answer for sentence (12a) can be different things for different children or one identical item for every child; $(12 b)$ can only be one identical thing made for all the children.

Sentence (13b) does not have the reading that 6 problems were solved as (13a) does: ${ }^{12}$

(13) a. ruguo liangge ren jiejue le sange wenti...

if two men solve Asp three problems

'if two men solved three problems....'

b. ruguo sange wenti, liangge ren jiejue le....

if three problems, two men solved

The facts presented so far seem to conflict with each other: the facts summarized in (8) provide evidence for reconstruction but those in (9-13) argue against it. Why is there such a conflict? We show below that this problem can be solved if we have a notion of "minimal reconstruction" - reconstruct only when necessary.

\subsection{Reconstruction}

Let us begin with the cases involving topicalized anaphors, which show the application of reconstruction in some cases but not in others. Comparing (6-7) and (9c-d), which allow reconstruction, and $(9 a-b)$, which do not allow reconstruction, we see that the important difference between them is that the displaced anaphor does not have a c-commanding antecedent in the former set but does have one in the latter set. In other words, in the cases of (6-7) and $(9 \mathrm{c}-\mathrm{d})$, the anaphor would not have a proper binder if it stayed in the topic position, according to Binding Principle A which requires an anaphor to be c-commanded (bound) by its antecedent within a certain domain (Chomsky 1981). By contrast, if the anaphor is reconstructed, the requirement that an anaphor must have a c-commanding binder would be satisfied and the sentence would be grammatical. The following sentences show the same point: even though (14b) is pragmatically less preferred than (14c), (14b) is better than (14c):

12 Conditional clauses are used here because a matrix clause generally requires a definite or specific subject $\mathrm{NP}$ and the constraint does not exist in conditional clauses (see Lee 1986, but also see Aoun and Li 1989). 
(14) a. shei/nage ren/meiren/meigeren ${ }_{\mathrm{i}}$ dou hen xihuan Wang laoshi gei ziji ${ }_{\mathrm{i}}$ de chengji who/which man/noone/everyone all very like Wang teacher give self's grade 'Who/Which person/ Nobody/Everyone likes the grade that Teacher Wang gave to self.'

b. Wang laoshi ${ }_{\mathrm{i}}$ gei ziji ${ }_{\mathrm{i}}$ de chengji, shei/nage ren/meiren/meigeren dou hen xihuan t Wang teacher give self's grade who/which man/noone/everyone all very like 'The grade that Teacher Wang gave to self, who/which man/no one/everyone likes'

c. ??Wang laoshi gei ziji $\mathrm{i}_{\mathrm{i}}$ de chengji, shei/nage $\mathrm{ren} / \mathrm{meiren} /$ meigeren $_{\mathrm{i}}$ dou hen $x$ ihuan $\mathrm{t}$ Wang teacher give self's grade who/which man/noone/everyone all very like 'The grade that Teacher Wang gave to self, who/which man/no one/everyone likes'

The displaced anaphor has a c-commanding binder within the displaced phrase; it therefore can satisfy Binding Principle A without reconstruction and no reconstruction takes place. The interpretation possibilities in (15) further show the lack of reconstruction of the displaced phrase:
Zhangsan $_{\mathrm{i}}$ yiwei, laoshi ${ }_{\mathrm{j}}$ gei ziji $\mathrm{i}_{\mathrm{i} / \mathrm{j} / \mathrm{k}}$ de chengji, Lisi $\mathrm{i}_{\mathrm{k}}$ kandao le $\mathrm{t}$. Zhangsan thought teacher give self DE grade Lisi see ASP
'Zhangsan thought that, the grade that the teacher gave to self, Lisi saw.'

On the other hand, in the cases like $(9 \mathrm{~b})$, reconstruction becomes more likely if the matrix subject is not a possible antecedent for the anaphor:

(16) a. gushi litou shuo, (ta)ziji ${ }_{i}$-de erduo, Daxingxing mozhe. story inside say (him)self's ear, Big Gorilla touch

'The story says that, (him)self's ear, Big Gorilla is touching'

The anaphor 'himself' must refer to an animate antecedent. 'Story' is inanimate and is not a possible antecedent for the anaphor, which therefore must undergo reconstruction to be interpreted. In (16b), the first person subject cannot be an antecedent for the anaphor, which must also be reconstructed to be interpreted:

(16) b. wo mengjian, taziji ${ }_{i}$ de erduo, Daxingxing ${ }_{i}$ mozhe.
I dream himself's ear, Big Gorilla touch
'I dreamed that himself's ear, Big Gorilla is touching'

In (16c), the plural matrix subject cannot be a possible antecedent for the anaphor, which is to be interpreted as bound by the embedded subject:

(16) c. tamen mengjian, taziji ${ }_{\mathrm{i}}$ de erduo, Daxingxing ${ }_{\mathrm{i}}$ mozhe.

they dream himself's ear, Big Gorilla touch

'They dreamed that himself's ear, Big Gorilla is touching' 
The discussion above shows that, even though the result of the experimental study by Chien et al. suggests the lack of reconstruction in the cases they studied, unexpected if topic structures can be derived by movement, this puzzling result invites us to examine further what motivates reconstruction and when it occurs. What we propose here is that reconstruction, in principle, is possible in the cases discussed by Chien et al. The experimental results are what they reported because of the type of examples used in the experiments. In these instances, reconstruction is not necessary because there is a possible antecedent to bind the anaphor at its landing site (sentences $(9 \mathrm{a}-\mathrm{b})$ ). When reconstruction is not necessary, it does not take place, a phenomenon predicted by the notion of last resort or minimal effort (see note (9)).

This conception of reconstruction also accounts for why the potentially dependent expressions such as 'same/different' in the topic position do not have the reconstructed interpretation (10): these expressions can be interpreted without an antecedent. The sameness or difference can be between the elements expressed by the head noun: the same or different things/students. Morpho-syntactically, they do not require a binder for interpretation. This also is the case with the lack of reconstructed interpretations for scope-bearing elements in the topic position such as quantifier phrases. These elements are not required to have a ccommanding antecedent morpho-syntactically. Therefore, they are not reconstructed. A $w h-$ word in the topic position can also be interpreted in the topic position and make the sentence a direct question. There is no need for it to be reconstructed to obtain an embedded indirect question interpretation.

If this line of pursuit is on the right track, the prediction should be that a pronoun would not need to reconstruct because it does not require a binder. A pronoun can be interpreted without a c-commanding binder. This prediction seems to be borne out: preposing the phrase containing the pronoun makes binding less likely than (17a-b) are significantly better than $(17 \mathrm{c}-\mathrm{f}):^{13}$

(17) a. Shei $i_{i}$ xihuan laoshi gei ta $a_{i}$ de chengji?

who like teacher give him DE grade

'Who likes the grade that the teacher gave him?'

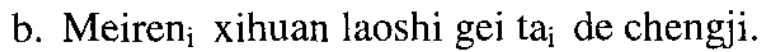

nobody like teacher give him DE grade

'Nobody likes the grade that the teacher gave to him.'

13 Speakers vary with respect to the possibility of a pronoun bound by a QP (Aoun and Li 1990). Most speakers, however, do find a contrast between a straightforward c-commanding binding of a pronoun and a backward (reconstructed) binding of a pronoun, even though they may differ in the acceptability of the backward binding. Those who dislike backward binding in general also dislike the sentence (i), even though (ii) is still good for them:

(i) taziji ${ }_{i}$ de chengji, meiren/shei ${ }_{\mathrm{i}}$ xihuan

himself DE grade noone/who like

(ii) $\mathrm{ziji}_{\mathrm{i}}$ de chengji, meiren/shei ${ }_{\mathrm{i}}$ xihuan

himself DE grade noone/who like

It is possible that taziji here is analyzed as a pronoun ta plus an intensifier ziji. 
c. ??laoshi gei ta $a_{i}$ de chengji, shei $i_{i}$ xihuan. ${ }^{14}$

teacher give him DE grade who like

'The grade the the tacher gave to him, who likes?'

d. ??laoshi gei ta $a_{\mathrm{i}}$ de chengji, meiren ${ }_{\mathrm{i}}$ xihuan.

teacher give him DE grade nobody like

'The grade the the tacher gave to him, nobody likes.'

e. Zhangsan ${ }_{j}$ yiwei, laoshi gei $\mathrm{ta}_{\mathrm{j} / *_{\mathrm{i}}}$ de chengji, shei $\mathrm{i}_{\mathrm{i}}$ xihuan?

Zhangsan think teacher give him DE grade who like

'Zhangsan thought, the grade that the teacher gave to him, who liked?'

f. Zhangsan ${ }_{j}$ yiwei, laoshi gei ta ${ }_{j} / *_{i}$ de chengji, meiren ${ }_{i}$ xihuan.

Zhangsan think teacher give him DE grade nobody like

'Zhangsan thought, the grade that the teacher gave to him, nobody liked.'

In order for the quantificational expressions 'who' and 'nobody' to bind the pronoun, the pronoun must be reconstructed to the c-command domain of these expressions. However, there is no inherent requirement for a pronoun to be bound. Because it does not need to be bound, reconstruction is not necessary and does not occur.

Briefly summing up, we show that the lack of reconstruction effects reported by Chien et al need not be surprising if we take reconstruction to be a process that takes place only when it is necessary. In the case of anaphors, if there is an antecedent for the anaphor at its landing site, the anaphor does not undergo reconstruction because it is not required to. In the case of pronouns, 'same/different' expressions, scope-bearing elements (including quantifier phrases and $w$-phrases), the reconstructed interpretation is significantly harder because they do not require a c-commanding antecedent morpho-syntactically. There is no requirement for reconstruction to take place.

To conclude the discussion in this section, we would like to point out that preposing of phrases containing names in Chinese shows the lack of reconstruction: the relevant facts, such as the acceptability of (18a-b), indicate reconstruction does not take place (see Huang 1993, Qu, 1994): $:^{15}$

14 The pronoun, even though not required to be bound, still needs a reference from the contexts (linguistic or non-linguistic). In the cases of $(17 \mathrm{c}-\mathrm{d})$, the backward binding of the pronoun by the QP is not totally impossible, since there is no clear interpretation for the pronoun elsewhere in the linguistic context. In contrast, the backward binding of the pronoun by the QP in (17e-f) is less likely, because Zhangsan can provide an interpretation for the pronoun.

15 The unacceptability of the following sentence cannot be due to reconstruction:

(i) ??[Zhangsan ${ }_{i}$ de nu pengyou $]_{j}, t_{a}$ hui jieshao $e_{j}$

Zhangsan DE girl friend, he will introduce

'Zhangsan's girl friend, he will introduce.'

Replacing the empty category $e$ with an overt pronoun (a base-generation structure, see the discussions regarding (7a-b)) does not improve the sentence:

(ii) ??[Zhangsan ${ }_{i}$ de nu pengyou $]_{j}$, ta $a_{i}$ hui jieshao ta ${ }_{j}$ Zhangsan DE girl friend, he will introduce her

'Zhangsan's girl friend, he will introduce her.' 
(18) a. Wo gei Zhangsan ${ }_{i}$ jieshao de nu pengyou, ta ${ }_{i}$ hui dailai. I to Zhangsan introduce DE girl friend he will bring 'The girl friend that I introduced to Zhangsan, he will bring along.'

b. ?Zhangsan ${ }_{i}$ de nu pengyou, wo xiwang Lisi hui jiao ta ${ }_{i}$ dailai. Zhangsan DE girl friend I hope Lisi will ask him bring 'Zhangsan's girl friend, I hope Lisi will ask him to bring along.'

We have shown that reconstruction in topic structures either does not occur or must occur, depending on the morphological properties of the displaced elements. This phenomenon can be understood as minimal reconstruction: reconstruction is taken as placing elements back and the process does not occur unless to satisfy the morph-syntactic constraint on the displaced element (greed, cf. Chomsky 1993, 1995). Some notion of economy or minimal effort governs the reconstruction possibilities. I would like to note here that it is not clear that such a notion of minimal effort must be thought of as a condition on the computation of grammar. It might as well be a condition on processing. The data we have does not argue for one way or the other. To speculate further, note that, if the facts discussed in the literature concerning the reconstruction of English $w h$-phrases having undergone $w h$-movement are correct (see some representative works, Chomsky 1981, 1995 for instance), they show that reconstruction of a wh-phrase in the Spec of Comp is always possible, even though there are no morphosyntactic requirements forcing the reconstruction (see Huang 1993, Heycock 1995, Takano 1995 for some complications of the facts). This might further point to the "processing" aspect of minimal effort in reconstruction: as mentioned, Chinese topic structures can be derived by movement or base-generated but the English wh-structures can only be derived by movement. It seems that when there are two options to interpret a structure, the one with less effort, i.e., the one without movement and reconstruction, is adopted. A more appropriate description of the facts we have discussed so far therefore might be the adoption of a simpler structure.

This seems to be also a driving force for the next issue to be discussed: when two syntactic structures are available for a sentence, the simpler one is chosen.

\section{Minimal projections}

There are many verbs in Chinese, essentially, resultative compound verbs [V1 (action) + V2 (result)], that allow both inchoative and causative usage, as illustrated by (19-21) (cf. Li 1993, Cheng and Huang 1994)

The unacceptability of these sentences, in contrast to those in $(18 \mathrm{a}-\mathrm{b})$ in the text might be due to some condition on the depth of embedding, as discussed in Reinhart (1981), Huang (1993, p. 106, note 4). The difference between adjunct and complement might not play a role here (see Johnson 1987, Lebeaux 1988, if indeed there is complement/adjunct distinction in Chinese pre-nominal de expressions), as the following sentence is still acceptable, like (18a-b), even though it is a typical case of complement. Also see Heycock (1995) for the distinction between arguments and predicates.

(iii) wo yao gei Zhangsan ${ }_{i}$ jieshao nu pengyou zhejian $s h i, t_{i}$ yizhi bu gan gen bieren jiang e. I want to Zhangsan introduce girl friend this matter he still not dare with others talk 'The matter that I want to introduce Zhangsan a girl friend, he still dare not talk to others.' 
a. Lisi mang-bing-le.

Lisi busy-sick-Asp

'Lisi got sick from being too busy.'

b. Zhangsan mang-bing-le Lisi.

Zhangsan busy-sick-Asp Lisi

'Zhangsan got Lisi to be sick from being too busy.'

(20) a. Lisi qi-si-le.

Lisi angry-death-Asp

'Lisi is angry to death (very angry).'

b. zhejian shi qi-si-le Lisi.

this matter anger-death-Asp Lisi

'This matter angered Lisi to death (extremely).'

(21) a. Lisi he-zui-le.

Lisi drink-drunk-Asp

'Lisi got drunk from drinking.'

b. zhe ping jiu he-zui-le Lisi.

this bottle wine drink-drunk-Asp Lisi

'This bottle of wine made Lisi drunk.'

What is interesting is that, even though there is an object following the causative expression, such an object cannot be topicalized: $(22 \mathrm{a}-\mathrm{c})$.

a. *Lisi, Zhangsan mang-bing-le.

Lisi Zhangsan busy-sick-ASP

'Lisi, Zhangsan got sick from being too busy.'

b. *Lisi, zhejian shi qi-si-le.

Lisi, this matter anger-death-Asp

'Lisi, this matter angered to death (extremely).'

c. *Lisi, zhe ping jiu he-zui-le.

Lisi, this bottle wine drink-drunk-Asp

'Lisi, this bottle of wine made drunk.'

Moreover, according to Cheng and Huang (1994), even though (23a) has both a regular transitive verb and a causative verb interpretation, the topicalized sentence loses the causative interpretation: ${ }^{16}$

16 The only interpretation for (23b) is that the child chased Lisi and the child got tired from the chasing. This is even clearer when the comment clause is embedded: 
(23) a. xiaohai ba Lisi zhui-lei-le.

child ba Lisi chase-tired-ASP

'The child chased Lisi tired.'

'The child caused Lisi to chase him tired.'

b. Lisi, xiaohai zhui-lei-le.

Lisi child chase-tired-ASP

'Lisi, the child chased him tired.'

Cheng and Huang (1994) observed that the unacceptability of sentences of the type of sentences in (22) and the reduced possibilities of interpretations in (23b) are due to a minimal parsing principle that favors processing the nuclear clause in its basic or minimally derived form. They suggest that the basic form of the nuclear clause is ergative in (19-22). The causative use of the verb is a derived structure (a causer (or a CAUSE verb) is added to the basic form). When the basic form of the nuclear clause is ergative, no null object is available to be coindexed with the topic $(22 \mathrm{a}-\mathrm{c})$. The lack of ambiguity in (23b) follows in the same way.

The notion of "minimal parsing" plays a major role in the interpretation of these sentences. Here we would like to elaborate on the notion of minimality and at the same time point out that it is not sufficient to simply make the distinction between derived and nonderived structures. It is necessary to make a distinction between the presence or absence of an object NP after the compound verb.

First, we need to clarify the interpretation of the relevant sentences (see note (16)). $\mathrm{Li}$ (1993) observes that a sentence like (24) that contains a compound verb [V1(activity)+V2(result)], 'chase-tired', can have three interpretations:

\section{Zhangsan zhui-lei-le Lisi.}

Zhangsan chase-tired-Asp Lisi

a. 'Zhangsan chased Lisi and Zhangsan got tired.'

b. 'Zhangsan chased Lisi and Lisi got tired.'

c. 'Zhangsan made Lisi tired from chasing him.'

Now, compare (24) with (25). Topicalization of the object NP not only loses the derived causative interpretation (24c) but also the second reading (24b) according to which the topicalized NP is the subject of the result verb 'tired':

(i) Lisi, wo zhidao xiaohai yijing zhui-lei-le.

Lisi I know child already chase-tired-ASP

'Lisi, I know that the child already got tired from chasing (him).'

If Lisi is to get tired, the BA or passive construction will be used:

(ii) Lisi, wo zhidao xiaohai yijing ba ta zhui-lei-le.

Lisi I know child already BA him chase-tired-ASP

'Lisi, I know that the children made him tired from the chasing.'

(iii) Lisi, wo zhidao yijing bei xiaohai zhui-lei-le.

Lisi I know already by child chase-tired-ASP

'Lisi, I know (he) is chased-tired by the children.' 
Lisi, wo zhidao/yiwei Zhangsan zhui-lei-le

Lisi I know/think Zhangsan chase-tired-ASP

'Lisi, I know/think Zhangsan has chased and got tired.'

On the other hand, there are sentences that also contain resultative compound verbs and that allow the topicalized NP to be the subject of the result verb:

na ping iu, wo zhidao/yiwei Zhangsan yijing he-guang le.

that bottle wine, I know/think Zhangsan already drink-empty-ASP

'That bottle of wine, I know/think Zhangsan has already consumed (and emptied) it.'

Note that the main difference between (24-25) and (26) is that the compound verb is threeway ambiguous when no topicalization takes place but he-guang in (26) can only have the interpretation that something (the bottle of wine) becomes empty because of an agent's drinking. Verbs of the former type contain a result verb (V2 in the compound verb) that can be predicated of the subject NP or the object NP (plus the derived causative use: three interpretations). Verbs of the latter type contain a result verb that can only be predicated of the object NP. More examples of the former type are: shuo-fan 'say-bored', ti-tong 'kick-ache', $q i$-lei 'ride-tired'. ${ }^{17}$ Examples for the latter type are: ti-po 'kick-broken', $z h u$ - $h u$ 'cookmushy', qi-huai 'ride-broken' etc. Another important distinction between the two types is that the former always allows an intransitive use and the latter is always used transitively. In other words, the sentences in $(27 \mathrm{a}-\mathrm{c})$ are acceptable without an object:

a. Zhangsan shuo-fan le.

Zhangsan say-tired Asp.

'Zhangsan got tired from speaking.'

17 Huang (1992) and Cheng and Huang (1994) note that with sentences like (i-ii), the definiteness of the object NP determines the interpretation:

(i) ta qi-lei-le ma le.

he ride-tired-Asp horse ASP

'He got tired from horse-riding.'

(ii) ta qi-lei le napi ma le.

he ride-tired that horse ASP

'He rode that horse and that horse got tired.'

In a topicalized sentence, however, the definite horse cannot be the one that gets tired (just like the interpretation of a sentence when $l e i$ is replaced by $n i$ 'tired/bored' which refers only to human beings). In order to express the horse being tired, either a BA structure or a passive structure is used.

(iii) (napi) ma, wo yiwei Zhangsan yijing qi-lei/ni-le.

that horse I think Zhangsan already ride-tired-ASP

'That horse, I think Zhangsan already rode and got tired.'

(iv) (napi) ma, wo yiwei Zhangsan yijing ba ta qi-lei-le.

that horse I think Zhangsan already BA him ride-tired-ASP

'That horse, I thnk Zhangsan already chased (it) tired.'

(v) (napi) ma, wo yiwei yijing bei Zhangsan qi-lei-le.

that horse I think already by Zhangsan ride-tired-ASP

'That horse, I think has already been ridden-tired by Zhangsan.' 
b. Zhangsan ti-tong le.

Zhangsan kick-hurt Asp

'Zhangsan got hurt from kicking.'

c. Zhangsan qi-lei le.

Zhangsan ride-tired Asp

'Zhangsan got tired from riding.'

In these cases, it does not matter what Zhangsan said, kicked or rode. The focus is on Zhangsan's being tired or hurt. The manner of getting tired or hurt is by the action of speaking (27a), kicking (27b) or riding (27c). Similarly, a sentence like (28) does not necessarily express someone being chased. It expresses the children's being tired due to some action of chasing:

xiaohai zhui-lei-le.

child chase-tired-Asp

'The child chased-tired.'

By contrast, the compound verbs that contain a result verb predicated of the object must have an object:

(29) a. Zhangsan ti-po le.

Zhangsan kick-broken Asp

'Zhangsan kick-broken (it).'

b. Zhangsan zhu-hu le.

Zhangsan cook-mushy Asp

'Zhangsan cooked (it) mushy.'

c. Zhangsan qi-huai le.

Zhangsan ride-broken Asp

'Zhangsan rode (it) broken.'

As indicated by the translation, the sentences in (29a-c) are not complete without an object. The sentences in (29), just like (26), can easily have an object and the object can be topicalized. There is no difference in interpretation between the topicalized and non-topicalized sentences.

(30) a. nage qiu, Zhangsan ti-po le.

that ball, Zhangsan kick-broken Asp

'That ball, Zhangsan kick-broken.'

b. nage cai, Zhangsan zhu-hu le.

that dish Zhangsan cook-mushy Asp

'That dish, Zhangsan cooked mushy.' 
c. naliang danche, Zhangsan qi-huai le.

that bicycle Zhangsan ride-broken Asp

'That bicycle, Zhangsan rode broken.'

Let us now return to (24-25). Recall that (25) has the reading of Zhangsan's getting tired from the action of chasing, but not the reading of Lisi's getting tired or Zhangsan's causing Lisi to chase him and getting tired (cf. (24a-c)). If there is a trace in the object position related to the topic, it is not clear why the two readings which require the presence of an object (being the causee or the one that got tired from Zhangsan's chasing) would not be available. Indeed, the unavailability of the reading according to which Lisi got tired from Zhangsan's chasing (24b) is not expected by Cheng and Huang's account because this is not a causative interpretation as the one in (24c). The question is why the reading in (24b) is no longer available when the object is topicalized. Note that this cannot be due to some identification requirements on which subject that the result verb (V2 of the compound verb) can be predicated of because of the acceptability of the sentences in (30a-c).

As a solution, we suggest that the nonambiguity of (25) is related to the fact that the verb of this sentence is just like those verbs in (27), which can be used as an intransitive compound verb syntactically. That is, the verb in (25) is interpreted as an intransitive verb. When it is an intransitive verb, the only interpretation would be that the subject is the one that did the chasing and got tired. The immediate question is how a topic NP is possible in (25) when the compound verb is an intransitive verb, without an object position to be associated with the topic. This is not a real question if we consider the fact that Chinese topics need not be derived by movement. They can be base-generated and be interpreted through a predication relation with the comment clause (an aboutness relation). In (25), since chasing can normally take a chasee, the aboutness relation most likely will derive the reading that Lisi is the chasee.

In brief, the compound verb in (24a-c) is used transitively (because of the presence of an overt object) but the same compound verb in (25) is a syntactically intransitive verb. The topic is interpreted not through its relation to an object of the compound verb but through a predication relation between the topic and the comment. The loss in the topic structure (25) of the reading in (24b) and (24c) follows from the different usage of the compound verb: even though the same verb can be used transitively (including the causative usage) and intransitively, only the intransitive usage is available to the topic structure. If this account is on the right track, the compound verb in (25) does not have the choice of obtaining the potentially available transitive usage and taking an object. Instead, the following generalization must hold:

If a verb need not take an object and it does not have an overt object, assume that it does not have an object in the syntactic representation. ${ }^{18}$

(31) not only accounts for the lack of ambiguity in (25), in contrast to the ambiguity in (24), and solves the problem raised against Cheng and Huang, but also accounts for the contrast

18 (31) is a statement on the choice of the presence/absence of an object when it is not required. In a $b a$ \$entence or a passive sentence (indicated by the morpheme bei), no such optionality exists. An object of the verb can occur as the NP following $b a$ in a $b a$ sentence. An object of the verb can also occur as the subject of a passive bei sentence. (31) thus is not relevant to ba and bei sentences. 
between the (b) sentences of (19-21) and (22a-c). Let us repeat (19b) and (21a) here for illustration:

b. Lisi mang-bing-le Zhangsan.

Lisi busy-sick-ASP Zhangsan

'Lisi got Zhangsan to be sick from being too busy.'

a. *Zhangsan, Lisi mang-bing-le.

Zhangsan Lisi busy-sick-ASP

'Zhangsan, Lisi got sick from being too busy.'

A compound verb 'busy-sick' does not need to take an object: someone can be busy and get sick and no other argument NP is needed, even though a causative structure may be derived by adding an extra argument, as in (19a). If a causative reading is intended, a causee occurs overtly in the typical object position, the postverbal position in this case. When the postverbal object is topicalized (22a) (therefore no overt object follows the verb), the sentence is interpreted as if there is no postverbal object. When no postverbal object exists, Lisi is the only argument that is related to being busy and sick. Since Lisi is the one being busy and sick, Zhangsan will have no interpretation and the sentence becomes unacceptable. The availability of a causative interpretation depends on the occurrence of the object NP overtly, which is lacking in (22a). ${ }^{19}$

In brief, some notion of minimal effort plays a role in determining the interpretation or acceptability of sentences with resultative compound verbs. When there is no overt verbal object, the structure behaves as if there is a trace related to the topic only when the compound verb requires an object. ${ }^{20}$ Otherwise, the sentence is interpreted as if there is no object position projected. In other words, if a position is subcategorized by the compound verb, it is projected; if it is optionally subcategorized and the object does not occur overtly, the object position is not projected. The choice of a syntactic representation thus seems to be subject to a minimality consideration. ${ }^{21}$

19 Unlike (25), an aboutness relation does not save this topic structure because 'busy' and 'tired' are not easily associated with any others than the one that is busy and that is tired. Moreover, just as mentioned in the previous note, a $b a$ or passive sentence can save the causative interpretation, because the object occurs overtly as indicated by $b a$ and $b e i$.

(i) Zhangsan, Lisi ba ta mang-bing le.

Zhangsan, Lisi BA him busy-sick Asp

'(Zhangsan), Lisi made him busy and sick.'

(ii) Zhangsan bei Lisi mang-bing le.

Zhangsan by Lisi busy-sick Asp

'Zhangsan was made busy and sick by Lisi.'

Relativization seems to behave in the same way, though some other factors seem to affect the interpretation (such as the occurrence of the aspect marker $l e$ ). More detailed investigation is needed.

21 In a causative sentence, a null CAUSE morpheme is present in the syntactic representation (see Huang 1992). The question is what difference exists between such a null morpheme being projected and the empty object not being projected when not required by subcategorization. An answer might lie in the difference between a head and a complement: a head is obligatory but a complement can be optional. This, however, is speculative and requires more examination of the nature of "minimal projections/representations." 
Such an account would predict that, when an object is required, movement of the object should still be possible, leaving a gap. We have seen that regular transitive verbs that require an object allow topicalization (30). $B a$ sentences and passivation are further examples. Let us briefly discuss passivization here. A passive sentence passivizes an object and, has morphological clues (the presence of the indicator of a passive sentence bei) indicating the obligatory presence of an object position. Because of the obligatory presence of an object position, the prediction should be that passivization of the object of a causative verb is acceptable. This prediction is born out, as the following passive sentences are all significantly better than their topicalized counterpart.

a. Zhangsan bei Lisi mang-bing-le.

Zhangsan Lisi busy-sick-ASP

'Zhangsan was made busy and sick by Lisi.'

b. Lisi bei zhejian shi qi-si-le.

Lisi, by this matter anger-death-Asp

'Lisi was angered to death by this matter.'

c. ?Lisi bei zhe ping jiu he-zui-le. ${ }^{22}$

Lisi by this bottle wine drink-drunk-Asp

'Lisi was made drunk by this bottle of wine.'

The contrast between topicalization and passivization further reinforces the conclusion we reached in section 1: topic structures can be moved or base-generated. When there are no morphological clues forcing the movement structures, the base-generation structure is adopted. Moreover, the choice affects the the decision of what syntactic structures a sentence has. That is, it plays a role in deciding on appropriate structural projections.

\section{References}

Abney, Steve. 1987. The English noun phrase and its sentential aspect. Cambridge, Mass: MIT dissertation.

Aoun, Joseph and Elabbas Benmamoun. 1998. Minimality, reconstruction, and PF Movement. Linguistic Inquiry 29: 569-597.

Aoun, Joseph, Lina Choueiri and Nobert Hornstein. 1999. Resumption, movement, and derivational economy. ms., University of Southern California and University of Maryland.

Aoun, Joseph and Yen-hui Audrey Li. 1989. Constituency and scope. Linguistic Inquiry 20.141-72.

Aoun, Joseph and Yen-hui Audrey Li. 1990. Minimal disjointness. Linguistics 28: 189-204.

Aoun Jopseph and Yen-hui Audrey Li, 1993. Wh-elements in situ: Syntax of LF? Linguistic Inquiry 24: 199238.

Barss, Andy. 1986. Chains and anaphoric dependence. Cambridge, Mass: MIT dissertation.

Cheng, Lisa and C.-T. James Huang. 1994. On the argument structure of resultative compounds. in In honor of William S-Y. Wang: Interdisciplinary studies on language and lauguage change. edited by Matthew Chen and Ovid Tzeng, 187-221. Taiwan: Pyramid Press.

22 Although the passive sentences are significantly better than the topicalized counterpart, some seem to be worse than the others. (32c), for instance, seems to sound less acceptable than (32a-b). It is not clear what the intervening factor might be. 
Chien, Yu-chin, Keneth Wexler and Shing-wu Chang 1993. Short and long-distance reflexives and the property of subject orientation. Journal of East Asian Linguistics 2: 229-260.

Chomsky, Noam. 1981. Lectures on government and binding. Dordrecht: Foris.

Chomsky, Noam. 1991. Some notes on economy of derivation and representation. in Principles and parameters in comparative grammar, edited by Robert Freidin. 417-454. Cambridge, Mass: MIT Press.

Chomsky, Noam. 1993. A minimalist program for linguistic theory. in The view from building 20: essays in linguistics in honor of Sylvain Bromberger, edited by Kenneth Hale and Samuel Jay Keyser. 1-52. Cambridge, Mass: MIT Press.

Chomsky, Noam. 1995. The minimalist program. Cambridge, Mass: MIT Press.

Goodall, Grant. 1987. On the argument structure and L-marking with Mandarin Chinese $b a$. In J. McDonough and B. Plunkett (eds.) Proceedings of NELS 17: 232-242. Amherst, Mass.:GSLA.

Goodall, Grant. 1989. Evidence for an asymmetry in argument structure. Linguistic Inquiry 20: 669-674.

Heycock, Caroline. 1995. Asymmetries in reconstruction. Linguistic Inquiry 26: 547-570.

Huang, C.-T. James. 1982. Logical relations in Chinese and the theory of grammar. Cambridge, Mass: MIT dissertation.

Huang, C.-T. James. 1984. Phrase structure, lexical integrity and Chinese compounds. Jounral of Chinese Language Teachers Association 19: 53-78.

Huang, C.-T. James. 1987. Remarks on empty categories in Chinese. Linguistic Inquiry 18: 321-337.

Huang, C.-T. James. 1989. Pro-drop in Chinese: a generalized control theory. In Osvaldo Jaeggli and Kenneth Safir eds., The null subject parameter, 185-214. Dordrecht: Kluwer.

Huang, C.-T. James. 1990. Complex predicates in generalized control. ms., University of California, Irvine.

Huang, C.-T. James. 1992. On lexical structure and syntactic projection. in Proceedings of Intenational Symposium on Chinese Linguistics and Language 3. Taiwan.

Huang, C.-T. James. 1993. Reconstruction, the A/A' distinction, and the structure of VP: some theoretical consequences. Linguistic Inquiry 24, 103-138.

Huang, C.-T. James and C.-C. Jane Tang. 1988. The local nature of long-distance reflexive in Chinese. NELS 18, 191-206. also in Long-distance anaphora edited by J. Koster and E. Reuland. 263-282. Cambridge: Cambridge University Press.

Johnson, Kyle. 1987. Against the notion SUBJECT. Linguistic Inquiry 18: 354-362.

Katada, Fusa. 1991. The LF representation of anaphors. Linguistic Inquiry 22: 287-314.

Lebeaux, David. 1988. Language acquisition and the form of the grammar. Amherst, Mass.: University of Mass. doctoral dissertation.

Lee, Thomas H.-T. 1986. Studies on quantification in Chinese. Los Angeles, California: University of California dissertation.

Li, Yafei. 1993. Structural head and aspectuality. Language 69: 480-504.

Li, Yen-hui Audrey, 1990. Order and constituency in Mandarin Chinese. Dordrecht: Kluwer Academic Publishers.

Li, Yen-hui Audrey. 1998. Argument Determiner Phrases and Number Phrases, Linguistic Inquiry 29: 693-702.

Li, Yen-hui Audrey. 1999. Plurality in Classifier Languages. Journal of East Asian Linguistics 8: 75-99.

Ning, Chun-yuan.1993. Theory of relativization in Chinese. Irvine, California: University of California dissertation.

Qu, Yanfeng. 1994. Object noun phrase dislocation in Mandarin Chinese. The niversity of British Columbia dissertation.

Reinhart, Tanya. 1981. Definite NP anaphora and c-command domains. Linguistic Inquiry 12: 605-635.

Saito, Mamoru. 1985. Some asymmetries in Japanse and their theorectial implications. Cambridge, Mass: MIT dissertation.

Shi, Dingxu. 1992. The nature of topic comment constructions and topic chains. Los Angeles, California: University of Southern California dissertation.

Shyu, Shu-ing. 1995. The syntax of focus and topic in Mandarin Chinese. Los Angeles, California: University of Southern California dissertation.

Sybesma, Ring. 1999. The MandarinVP. Dordrecht: Kluwer Academic Publishers.

Takano, Yuji. 1995. Predicate fronting and internal subjects. Linguistic Inquiry 26: 327-340.

Ueyama, Ayumi. 1998. Two types of dependency. Los Angeles, California: University of Southern California dissertation.

Xu, Liejiong. 1986. Free empty category. Linguistic Inquiry 17, 75-94.

$\mathrm{Xu}$, Liejiong and D. Terence Langendoen. 1985. Topic structures in Chinese. Language 16, 1-27. 